\title{
The Intertwinement of Spiritual and Local Healing Practices Among the Gurage People of South-Central Ethiopia
}

\author{
AKMEL MOHAMMED USMAN (PhD) \\ WOLKITE UNIVERSITY, Department of Sociology, P.O.B. 07
}

\begin{abstract}
This study mainly focuses on the Syncretized processes and practices of scriptural and local healing and its interlacement with extraordinary healing power of traditional cults that have been ubiquitous for centuries among the Gurage ethnic groups who mainly inhabit the south central Ethiopia. Following the introduction of Islam and Christianity into the Gurage Land, the newly converted into either of the two religions, especially those agents of traditional cults, were remained claiming that they have an extraordinary power to cure diseases which were previously believed to be healed only through performing traditional ritual rites. This study also intends to explore the extraordinary heal power of the traditional deities that are used to cure various kinds of diseases through their ritual agents. Thus, an ethnographic study on the processes and practices of spiritual knowledge of healing will be carried out and how ritually sanctified disease, which were defined under the frame of the Sufi Islam religious denominations, especially the Sufi shrine of Abret, are cured. The main data gathering tools that are opted for employing in the selected research area are unstructured and semi structured interview, focus group discussion and participant observation.
\end{abstract}

DOI: $10.7176 / \mathrm{JAAS} / 58-02$

Publication date:September $30^{\text {th }} 2019$

\section{i. Introduction to the Study \\ Brief Description of the Study Area}

The Gurage People are one of the ethnic groups of Ethiopia who are living in the south central highland part of the country. The Gurage Land is currently divided into two main parts that include Eastern Gurage and Western Gurage. The division of the two parts of the Gurage land is based on some common denominators such as dialectical differences and geographic locations the ethnic groups inhabit in the region share.

With the downfall of the military government of Dergu in 1991, the Gurage people were politically organized as one of the fourteen newly established regions, with a newly coined name of region seven (kilil sebat). Region seven (kilil sebat) was comprised various sub ethnic groups of the Gurage ethnic groups, Hadiya ethnic groups, Kambata and the Qabena. However, as a result of the political administrative restructuring following the 1994 national election, the region seven (kilil sebat) was merged into the newly modified region of the Southern Nations, Nationalities and Peoples Region, and it was reduced into the level of zonal administration. Following this administrative change, the Gurage zone was established with its zonal capital of Wolikite. The zonal town Wolkite is located at a distance of one hundred fifty kilometers to the southwest of Addis Ababa.

Hence, as it is mentioned above, currently the Gurage zone consists of the Eastern Gurage that comprises the Sodo Gurage who speaks Sodigna, the Masqan who speaks Masqanigna, the Dobi Gurage who speaks Dobigna and the Western Gurage that commonly named as the Sabat Bet Gurage, which includes seven tribal groups and is the focus of this study.

\section{Problem Statement and Methodology}

Along with the Gurage People, there is a long tradition of using medicinal plants to treat a variety of ailments. One can assume the major reasons for the preference of medicinal plants among the Gurage ethnic groups such as the trust the communities have in traditional medicine, due to culturally linked traditions, and relatively low cost in using them. Thus, it is the main objective of this study to investigate the syncretic processes and practices of traditional medicine in the Sabat Bet Gurage in two perspectives. The main focus of this study is about the syncretization of spiritual healing practice, which is one form of traditional medicine, with local healing practice among the Sabat Bet Gurage people.

Studies so far conducted in Christianity and Islam are seldom agreed on the exact date in which the two scriptural religions came to the Gurage region. Of course, like any regions of Ethiopia, this particular areas have been underwent both the influences of Christianity and Islam and the interplay of different religions. As it is argued by Worku (1991) and Aleqa Taye (1966) Christianity was introduced into the Gurage land in the fourteenth century following the military expedition led by Azmach Sibhat. Moreover, it is believed that Islam was introduced into the region by Muslim merchants to whom they came shortly after the long distance trade routes, which traversed to the Gurage region from the coast (Trimingham, 1952).

Since the propagation of Islam and Christianity into the Gurage land in the $19^{\text {th }}$ century, some of indigenous institutions of healing, which were highly intertwined with indigenous belief systems, were continued 
accommodating with the newly established religious denominations. The willpower of a spiritual healing force that was adopted from the indigenous belief systems was syncretized into the frame of Christianity and Islamic religions. The converted individuals into Islam and Christianity, who claimed they had extraordinary spiritual healing power, were redefined their traditional position in line with the newly propagated religions. For instance, the agency role of the Maga, who were assistant of head of the Bozhe cult (thunder god), was redefined into its Islamic and Christian form through taking the responsibility of preaching about the new scriptural religions besides performing the miraculous spiritual healing power. The Magas, who came from a specific clan and their office was transferred hereditarily through the senior line of the male members, were agents of the Gwetakuya in the clan districts of the Sabat Bet Gurage. They provided healing services and ritual protections to the adherents of the Bozhe traditional cult, a thunder god represented by lightning, who were thought to be inflicted by sacred illnesses and reciprocally they collected tributes under the authority of the ritual functionary. However, Christian and Muslim Magas gradually abandoned their agency role to the representative of the Bozhe cult and associated the source of their extraordinary power of healing diseases with Christian and Muslim saints and prophets.

Therefore, it is the intent of this study to give twilight on the syncretic formation of traditional healing practice that is occurred between different religious denominations; mainly the Islamic shrine of Abret and the traditional Bozhe deity, that make for the constitution of a new spiritual healing institution.

Regarding with research methodology, this study has been conducted through applying qualitative data that were gathered from research sites. For this reason, fieldwork was conducted in the selected sites of Enemor ina Enner, Wolkite, and Addis Ababa. Enemor ina Enner is main study center wherein the two religious shrine of the traditional Bozhe deity and the Islamic shrine of Abret, which are important centers of traditional and spiritual healing, are established. For that reason, I selected these sites to make the study complete through analyzing the syncretic nature of the practice of traditional healing practices at different religious and social institutions. Altogether, the fieldwork has been taken fifteen months between May, 2017 - July, 2018. For the purpose of this study, an ethnographic approach, which is the major element of qualitative research style, was applied. Besides, to channel field data into established academic perspectives, extensive survey of anthropological, historical and indigenous knowledge system literature has been made.

The methods that were applied in the course of accomplishing the research include informal interview, semi-structured interview, focus group discussion, participant observation, case studies and secondary sources. The data sampling method that has been applied were snowball and respondent- driven sampling, which were commonly referred as network sampling methods (also known, chain referral methods).

\section{ii, Rituals and Healing Practices of Bozhe Cult and Power Sharing with Abret Shrine}

Before the advent of Christianity and Islam into the Gurage land, the different tribal groups of the Sabat Bet Gurage, which are the focus of this study, were worshipers of traditional religions. The three main ritual cults that had been worshipped by the Sabat Bet Gurage were Waq', Bozhe and Demwamit. The ritual cults of Bozhe and Demwamit were worshipped by the whole Gurage, except the tribal groups of Muhi'r wherein Christianity has survived from long ago. Even though Waq' was worshipped by all Gurages, each tribal group of the Sabat Bet Gurage had their own Waq' with local names.

However, with the introduction of Christianity and Islam into the Gurage Land the three traditional ritual cults were highly influenced through the accommodated relationship followed by the two scriptural religions. Hence, among the three traditional deities, it is the focus of this study to scrutinize the syncretic processes carried out between the Bozhe traditional cult and the Sufi shrine of Abret.

The Bozhe ritual cult (Thunder god) is one of the traditional worship systems among the Sabat Bet Gurage and its representative was known as Yinangara Gweta, addressed as Gwetakiya who was living in a sacred place of Inangara village and his assistants were known as Maga. The Gwetakiya was belongs to the male member of the Entezera clan of Enor tribe. The Gwetakuya ritual position was hereditary, which was transferred from father to the elder son keeping its primogenitor lines. Like the cult of Waq', there was an annual ceremonial celebration for the ritual spirit of Bozhe, which was known as Nipwar. It was celebrated annually in all parts of the Sabat Bet Gurage, except Muhir, where the ritual agents of Gwetakuya exalted tribute.

The Gwetakuya assigns his representatives, who were known as Maga to the different tribes of the Sabat Bet Gurage in order to exalt tribute from the worshipers of Bozhe (Thunder god). The gifts were offered in the forms of honey, wheat, bulls, umbrella, enset, and money. The worshipers of Bozhe in the Sabat Bet Gurage believed that the thunder god could mete out fatality and burn properties through lightning. For this reason the Gurage payed tribute to Bozhe to 'receive ritual protection against the destruction of their property by lightning, the principal manifestation of the deity. He also provides ritual safeguards against theft, and the sacred paraphernalia, the $\dot{S} a n a$, used for protection against fire and theft, is distributed throughout Gurage by his ritual agents, the Maga' (Shack, 1966).

However, since the $19^{\text {th }} \mathrm{c}$., the native peoples of the Sabat Bet Gurage who had long been worshipers of traditional religions had been highly influenced by the proselytized mission of Islam and Christianity. From this 
time onwards, through the processes of the localization of the two universal religions of Islam and Christianity, there have been two important developments that affected the socio-religious life of the people of Sabat Bet Gurage. The first dynamics came about when both religions of Islam and Christianity were absorbing some elements of the traditional religious practices through processes of indigenization and then formed new forms of syncretic ritual elements. The second attribute that has been observed since the conversion of the worshipers of traditional deities either to Christianity or Islam was that the newly converted continued practicing some rituals of the traditional deity even after their conversion.

The first underlying cause of alteration in the social-religious organization of the Sabat Bet Gurage people has certainly taken place during the early conversion of adherents of the traditional belief system either to Christianity or Islam. One typical example of such processes was demonstrated when the ritual dignitary of the Bozhe cult converted to Islam by abandoning his ritual position to the traditional deity. This routine of religious conversion left segmented the hereditary lineage which has vested rights in the ritual position of representing Bozhe. The segmentation of the hereditary lineage into two religious polar opposites resulted in the sharing of the traditional ritual power of Bozhe between the senior line which adopted Islam and the junior collateral line which held onto its traditional vocation. While the office of Gwetakuya (ritual title of the dignitary) was inherited by the junior line, many old followers of the former senior functionary held a strong belief in his traditional ritual power shared with the junior line to mediate with Bozhe and they carried their spiritual allegiance over to him by adopting Islam as he had done. As a consequence of the doubling mediating roles that came from the shared traditional ritual power that served to defend a tight association with Bozhe and the new spiritual situation in the epithet of Allah, the splinter group led by the elder ritual leader gained followers.

Furthermore, the traditional ritual power that was shared through negotiation between the two segmented groups got defined and redefined into the frame of Islam essentially during the second and third generations of the early convert to Islam by abandoning his dignitary position to the Bozhe cult. During the second generation, Abret was established first as a zawiyya and then evolved into a shrine when Yaquba was founded as a hallowed spot/place, where the tombs of the first and second generations located, by sheyikh Budalla and then began to be visited by their adherents. Although sheyikh Bushra shared a portion of land from one end of the Inangara village, which is a sacred place of the Bozhe cult, argued with the dignitaries of the Bozhe cult as it was part of the Islamic sacred place because of the comportment of his father's tomb in that respect, his primary objective was to incorporate the ritual power that was supposed to be transferred to the senior line through his father together with his Islamic position of Sheyikh, for the proselytization of Islam into the worshippers of the traditional Thunder god.

Despite the fact that sheyikh Bushra founded the zawiyya of Abret as the first Islamic learning center in the Sabat Bet Gurage, his activities on the expansion and proselyitization of Islam was limited in the village of Abret. It was during the third generation of sheyikh Budalla Islam has been spread out into most part of the Sabat Bet Gurage through processes of accommodation and syncretization. To capture the traditional spiritual power of the Bozhe agents that is highly revered and honored by the Sabat Bet Gurage peoples, sheyikh Budalla seemed to have looked for areas of articulation between the Bozhe deity and Islam as well for the transmutation of the latter into the local setting. To facilitate transition and build his religious authority sheyikh Budalla redefined most of the components of Bozhe ritual practices and organizational structure into the material body of Islam.

The formation of the Qubba shrine in the sacred village of Inangara during the third generation is one of the systematic ways of 'positive competition' with the hallowed shrine of the Bozhe deity in the region. Equally it is held from the empirical data that most of the ritual practices in the Qubba shrine are Syncretized ritual elements which were taken from the Bozhe ritual practices during the third generation.

The new converts to Islam make a pilgrimage to the sacred village of Inangara, where the two shrines of the Bozhe cult and the Qubba of the Sufi Islam are located, at least two times each year to celebrate Nipwar and mawlid in the respective shrines. Some elements of the ritual practices that are performed by the Muslim practitioners of the Bozhe deity besides attending the annually celebrated Nipwar ceremony are the ritual of seeking sacred protection from lightning, protecting property from theft, the ritual of retaliating enemy through ritual sanction (wakashe siqrot). These ritual practices had not been incorporated into the frame of Islam, thus most of the aspirants of the Abret sheyikh continue practicing it. On the other hand, the spiritual leaders of the Abret shrine had never attempted to disintegrate the traditional religious institution of the Bozhe cult. However, the Abret sheyikh completely appropriated the remaining two deities of Waq and Demwamit, which were worshipped by the Gurage peoples for centuries akin to Bozhe, into the frame of Islam. While Waq was substituted by Allah, the female goddess of Demwamit was replaced by sitti Fatima, daughter of Prophet Mohammed.

\section{Iii, Amalgamating traditional healing practices into Sufi Islam}

Since the second half of the nineteenth century the Sufi Islam has been propagated into the Sabat Bet Gurage at the times of the second and third generations of the Abret shrine, sheyikh Bushra and sheyikh Budalla 
respectively. During this time indigenous religious elements which were found accommodated to the Sufi Islam were taken over in their syncretic forms. The cult of Waq (sky god) that was the central force uniting Gurage men of all tribes was Syncretized into the frame of the Qadiryya teriqa of the Sufi order. Accordingly, the founders of the Abret shrine, sheyikh Bushra and sheyikh Budalla were appropriated the indigenous religious and healing practices which were related to Waq into the structure of Sufi Islam.

The willpower of a spiritual healing force that was adopted from the indigenous belief systems was one of the major criteria to claim the office of a sheyikh in the Sufi order. This extraordinary healing power was mostly manifested by the performance of a karama (miracle). Thus the primary focus of the oral narratives that share with the miracles of the Abret Sheikh was rotating around his healing ability. Most informants prefer to narrate the healing power of Sheikh Budalla through mentioning the types of sickness that ranging from deafness to mental illness and which were eventually healed by him. There are numbers of oral traditions that handle onthe karama (miracles) which were conceived to be executed by the Abret Sheikh. One can reason that the performance of karma can be seen as the trademark of the Abret Sheyihk through analyzing the manner how the aspirants (murid) of the Abret Sheikh express their sheyikh's extraordinary power when they narrate about his spiritual leadership qualities.

The Abret murids had been visited sheyikh Budalla at times of health crisis through seeking his spiritual healing power. The local narratives contended that the healing service of the Abret Sheyikh was not restricted solely to the Muslims, but there were numbers of Christian Gurages who came to him and cured of their ailments. There was some other way of healing from physical or mental illnesses in addition to the personal treatments and Duwa of the Abret Sheikh. The murids collected a sample earth (locally termed as worq afer) from the soil where the Abret Sheikh walked and they drank or rushed it on the part of their sick body, believing that it could cure them from diverse cases of diseases. Subsequent to his attendance at the annually celebrated mawulid at Abret, Shack (1969:193) has underscored his observation on the ritual practices of the pilgrims as follows;

Pilgrims often return with samples of the earth collected from around the shrine, and especially from where Shehoch, has walked, or his sacred white mule has trotted. This earth is held to be sacred. A potion said to have special spiritual and curative powers is made from the sacred earth and is drunk on occasions when a spiritual uplift is needed.

In addition to that, for the purpose of augmenting his spiritual and political power, sayyid Budalla had expanded his area of influence into the districts of Sabat Bet Gurage through adopting indigenous structures into Sufi Islam. Accordingly the agency role of the maga was redefined into its Islamic form of the Sufi order that responsible for preaching about Islam and disseminating a religious propaganda about the miraculous spiritual and healing power of sayyid Budalla as he was bestowed by Allah. The magas, who came from a specific clan and their office was transferred hereditary through the senior line of the male members, were agents of the Gwetakuya in the clan districts of the Sebat Bet Gurage. They provided healing services and ritual protections to the adherents of Bozhe who were thought to be inflicted by sacred illnesses and reciprocally they collected tributes under the authority of the ritual functionary.

In view of that, sheyikh Budalla adapted the institutional structure of maga ritual agents within the framework of Sufi Islam and he then appointed some of the hadims, who acquired traditional religious knowledge in Abret, as his ritual agents in the clan districts of the Sebat Bet Gurage. After the religious agents of Abret established themselves that was resulted by the foundation of a zawiya in plots of lands acquired either through purchase or endowment (waqif), they evolved into a new religious status of deputy sheyikh (naib). One of the contributing factors for the transformed status of the religious agents into the deputy sheyikh status in their respective district was because they received the blessings (baraka) of sheyihk Budalla to give spiritual healing services. Despite the fact that the deputy sheyikhs' religious authority was limited to their respective clan district that was delineated by the Abret Sheyikh.

\section{Iv, The Interlaced Forms of Contemporary Spiritual Healing}

Based on the data obtained in the study area this study argues that most Muslims have faith on spiritual healers than visiting modern health centers when they feel ill. One can mention some factors that resulted for the preference of the spiritual healers in the rural community that may include the Muslims build trust on the competency of the spiritual healers believing that their power was granted from Allah, besides the affordable price they need to pay to the service when compared with the relatively expensive modern health service.

In the previous section, a discussion was made in the process of the syncretization of indigenous

religious institutions into the frame of Sufi Islam, which has been spearheaded by the spiritual leaders of Abret. In due processes of accommodation, the spiritual leaders of Abret either appropriated or adopted ritual elements from the three ritual cults of Waq, Demwamit and Bozhe and then they defined it into the frame of Sufi Islam. This process of the Islamization of the indigenous ritual institutions is holistic in its nature, besides its religious functions, it includes ritual institutions of healing and justice. At the present time the healing practices that result from the developments cited in this paper have formed their own peculiar shapes and features. Hence, 
established in the accounts of informants, the healing practices in contemporary Sabat Bet Gurage can be framed in the discussion that is illustrated below.

In the first place, the healing practices that are provided at the Abret shrine have been given a preponderant position among the Muslim Gurages. Most murids (aspirants) of the Abret Sheyikh still believe in the extraordinary healing power of the families of sheyikh Budalla, they visit the Sheyikh's relatives who claim to possess this power to cure ailments. Sayyid Miqbas is one of the families of the Abret Sheyikh, who give spiritual healing services not only to the Muslims, but also to the adherents of other religions. Sayyid Miqbas, who is the elder son of sheyikh Budalla, gives medicines for various types of illnesses such as mental disorder, paralysis, back-pain, liver diseases and cancer. Mental illnesses are viewed equally the outcome of malevolent spirits that are fixed into its Islamic forms named as jinn, and are treated with prayers. In addition to scriptural texts and prayers, Miqbas uses herbal and animal remedies for treating many diseases. Hence, the Syncretized forms of healing practice that combine spiritual healing power and the traditional knowledge of local medicine by sayyid Miqbas has contributed for the multitude of his clients who come from different religious denominations.

Also, among the deputy sheyikhs who were appointed by sayyid Budalla as his agents (naib) in various districts of the Sabat Bet Gurage, there are even some of them pass on spiritual healing services claiming that the Abret Sheyikh had granted them permission (ijaza). Considering the extraordinary healing power, the deputy sheyikhs claim that they belong to the same clan of the Abret Sheyikh which was believed to be genealogically descended from the Qurayyish tribe of the Prophet, and then his baraka was transformed to them through this line. Some of the deputy sheyikhs are known by their specialization in healing illnesses. For instance, sayyid Fereh, who is the cousin of the Abret Sheyikh is known by his spiritual skill of healing a mentally disordered person. There are more deputy sheyikhs in different districts of the Sabat Bet Gurage who are nominated by the locality they inhabit, for illustration, ya qafa sheyikh (to name the sheyikh of the locality of Qafa), ya Kahsay sheyikh (the sheyikh of Kahsay locality). The spiritual position of these sheyikhs is mainly associated with healing services.

In addition to the personal healing services that are put up by the families of the Abret Sheyikh, the Muslims of the Sabat Bet Gurage use two main sacred objects, earth sample of the Qubba sanctuary and qulet spring water, to heal illnesses. When pilgrims come to Qubba and finish their ritual prayer, they come out of the ritual area of the sanctuary by collecting samples of the sacred earth from the ground of the sanctuary. While male pilgrims collect samples of the earth from the ground of tombs, the women collect it from the ground of the fence of the sanctuary. Most pilgrims believe that this particle of soil, commonly known as werq-afer (the golden-soil), is sacred and have special spiritual and curative power. According to the accounts of some informants, the pilgrims take the sample earth of Qubba to their home and use it in two forms; either they use it in liquid form by mixing with the holy water of qulet or on its dry form rush it on the part of the body they feel pain. The use of earth sample collected from the sanctuary of Qubba for healing practice is resembles with the healing practice of the Orthodox Church its adherents use two types of sacred elements, incense ashes and soil, together known as emnet.

\section{v, Conclusion}

In the present situation, the various forms of spiritual healing practices are continuing vital among the Muslims of the Sabat Bet Gurage. The long process of syncretic mechanics and accommodation of indigenous belief systems into the frame of the Sufi Islam is one of the contributing factors for the longevity of the spiritual healing practices among the Gurage people. For most of the aspirants of sayyid Budalla, beyond its function in curing illnesses, the spiritual healing also augments their mental readiness to perform regular religious rituals. Muslim and Christian adherents who visit the Bozhe and Waq shrines respectively, seeking the assistance of the head of the shrines to get cured some of the diseases that have been healed by traditional religious leaders. Hence, this study finds out that albeit the Abret Sufi shrine accommodated some of the heal power of the Bozhe into the frame of sufi Islam, the converted adherents of the shrine still continuing visiting the heads of the traditional deities.

\section{REFERENCES}

Alemayehu Neri Wurgaso. 1983. Esàt the Culture of Gurage and Ethiopian History. Bole Printing. Addis Ababa (Amharic).

Aleqa Taye. 1966. The History of Ethiopia. Addis Ababa (Amharic).

Amira Kedir. 2014. The Qatabare Sheikh, MawlidCelebration and Intra- Faith Debate on the Mawlid Celebration. MA Thesis. Addiss Ababa University.

CSA.2007. Federal Democratic Republic of Ethiopia (FDRE) Central Statistics Agency

Dinberu Alemu, et al. 1995. Goggot the History of the Gurage Ethnic Groups. Wolkite (Amharic).

Dineka Kornema.1998. "The Celebration of Abret Mawlid and its Practices". BA Thesis. Addis Ababa 
University (Amharic).

Gebreyesus Hailemariam. 1991. The Gurage and Their Culture, Vantage Press, Inc.

Jai, Kishan and Akmel Mohammed. 2016a. Syncretic Forms of Spiritual Healing Practices Among the Muslim Gurage of Southwestern Ethiopia. Journal of Philosophy, Culture and Religion, 17, 1-5. 2016b. The Ethno History of The Sabata Bet Gurage Peoples Of South Western Ethiopia. International Journal of Multidisciplinary Educational Research, 4 (12), 131-146.

Ladislav Holy. 2006. Religion and Custom in a Muslim Society: The Berti of Suda. Cambridge University Press, Cambridge

LeBel, Phillip. 1974. Oral Tradition and Chronicles on Gurage Immigration. Journal of Ethiopian Studies. 12 (2), 95-106.

Renard, John. 2005. Historical Dictionar of Sufism. The Scarecrow Press, Inc. Oxford.

Seifu Dibabe. 1974. Azmach. Addis Ababa: Tesfa, G. S.

Shack, W. 1966. The Gurage: A People of Enset Culture. Lond: Oxford University Press. 1961. Religious Ideas and Social Action in Gurage Bond-Friendship. International African Institute. 33 (5), 198-207.

1977. "On Deus Otiosus In Gurage Religious Traditions After the Accession of Menelik II". Proceedings of the Fifth International Conference of Ethiopian Studies, 491-499. Nice. 1966. Guilt and Innocence: Problem and Method in the Gurage Judicial System. Eighth International African Seminar, Haile Sellasse I University.

Shack, William, and Habtemariyam Marcos. 1974. Gods and Heroes: Oral Traditions of the Gurage of Ethiopia. Oxford University Press.

Worku Nida. 1991. Jebdu: The Gurage Culture and History. Addis Ababa. Bole Printing Press. 